\title{
ROLE OF ACADEMIC LIBRARY TO ENCOURAGE STUDENT COMMUNITY ABOUT THE IMPACT OF YOGA IN MODERN AGE: AN OVERVIEW
}

\author{
BELA MONDAL ${ }^{1} \&$ SABYASACHI HALDAR ${ }^{2}$ \\ ${ }^{1}$ Librarian, Raniganj Girls, College, Searsole Rajbari, Paschim Burdwan, West Bengal, India \\ ${ }^{2}$ Librarian, Familia School, Chougacha, West Bengal, India
}

\begin{abstract}
In the modern age, people have become a machine working from the morning till sunset; almost all sections of the population have become mechanical machines. Student Community (School Student, college Student, University Student) are no exceptions to this. Now a day's student's life are stuck between school, college, exams, sports, tuitions and many other activities, which result in their mental and health disorders. In the modern age student's life revolves around academic activities, assignment, to score good grades in the examination, performing better at the academic institute and a lot of their hectic activities. They don't get much time for themselves or to relax their mind. To get first in the race of life, they lack somewhere behind and alleviate more and more stress for themselves. The marathon of sitting from morning to evening throughout their school time makes their body rigid, hard and stiff. Most of the student lacks the much needed flexibility in their physical body. The hardness and rigidness of their body, naturally affect their mind, which in turn affect their studies. To attain a flexible body and healthy mind, Yoga practice is indispensable one. For completely healthy bodily function Yoga has great importance. Yoga can help student community in many ways. It helps to attain perfect equilibrium and harmony for body and mind, strengthens internal organs, promotes self-healing, removes negative blocks from the mind and toxins from the body, enhances personal power, increases self-awareness, and helps to attain focus and concentration. In this regard, Academic Institution as well as Academic Library plays a very important role to promote Yoga in student community.

KEYWORDS: Academic Library, Academic Institution, Student Community \& Yoga \& Modern Age
\end{abstract}

Received: Jul 12, 2017; Accepted: Jul 29 2017; Published: Aug 01, 2017; Paper Id.: IJLSRAUG20174

\section{INTRODUCTION}

In modern age people have become over-ambitious; their desires have no ends. They are always engaging with their activity and achievement of their own and other family members. Student community are not apart from them. In this competitive world the students experience extreme stress in different situations. Stress affects both the body and mind. Constant presence of stress in modern life is a matter of concern as it affects all aspects of a students' life and may also cause disease of various parts. Students may be young, they are not immune to stress. Academic learning attained in a subject or group of subjects after a long period of instruction, Excessive stress hampers students' performance. Nowadays students' life revolves around academic activities, assignments, sports, tuitions and many other activities which results mental and health disorders.

In this regard yoga has been recognised as an important tool to manage stress. Yoga offers multiple benefits to a modern day student and helps in increasing stamina in their body to perform different activities actively. Yoga has proved to be of great benefit in mental health. Yoga helps to promote a balanced, healthy and confident life. 
In this aspect academic library can play an important role, to make students aware, about the impact of Yoga for student community, in modern age.

\section{OBJECTIVES}

\section{The Following Objectives of the Study Are as Follows:}

- To know the relevance of Yoga in students community in this modern age.

- To aware the students about how Yoga influences memory, intelligence, creativity and concentration.

- To know the role of Academic Institution as well as Academic Library regarding importance of Yoga.

- To create a platform indirectly through the Academic Library for student community to built their physical and mental health.

- To provide information and resources related to Yoga among students for their all over development.

\section{IMPACT OF YOGA ON STUDENT COMMUNITY}

Yoga is an art science of healthy living. It is a spiritual discipline based on an extremely subtle science, which focuses on bringing harmony between mind and body. The holistic approaches of Yoga are well established and it brings harmony in all walks of life and thus known for disease prevention, promotion of health and management of many life style related disorder. It is a way of living whose aim is 'a healthy mind in a healthy body.

In case of student community a piece of Yoga practice every day will definitely make them gain more physical strength and get rid of all physical difficulties and disease. With this mental strength, student community can come out and fight against all discrepancies with increasing self-confidence. If practiced regularly, Yoga yields some progressive result that can be quite beneficial for student community. Some proven studies have revealed that Yoga have a biochemical effect on the human body that resembles the benefits of antidepressant and anti- anxiety medications and thus can help a lot to reveal that in addition to reduce Adrenaline production, Yoga decreased production of the neurotransmitter dopamine( lower dopamine levels produce an overall feeling calm) ${ }^{[5]}$. For completely healthy bodily function Yoga has great importance. Yoga can help student community in many ways that includes ${ }^{[11]}$ :

\section{DE-STRESS STUDENTS}

Family pressure, academic performance standards, financial fear and peer groups are some of the reasons which may take a student's success in school. One of the primary benefits of yoga is to eliminate stress from young students. According to behavioural health services and research it is found that a student who participated in yoga instead of physical education has more exhibited improvement in mood, perceived stress and anxiety. Yoga and its movement help in drawing focus away from the busy and hectic day and reflect calming effects on your body. Students will feel happier and have improved mental focus and concentration after practicing yoga and meditation.

\section{SHARPNESS AND CONCENTRATION}

Yoga has proved to be of great importance in increasing concentration power and sharpness of brain. Movements of yoga offer time for mind and body to relax and include increased focus on long, deep, slow breaths as well as coordination of mental concentration. Yoga focuses on peace of mind. 


\section{STRENGTH}

Strength is very important especially for young people who struggle between rigorous activities all round the day. Yoga and meditation helps in increasing muscle strength if practiced regularly. All yoga poses helps to build your deep abdominal muscles and core strength, which helps you in performing your daily activities quickly. With meditation and yoga, you tend to get a great deal of strength and calmness of mind.

\section{HEALTH BENEFITS}

Health therapy is the most important benefits of yoga. It has been reported that conducting yoga has succeeded in improving asthma. Asthma can be controlled by doing yoga regularly. Yoga practice also results in low level of anxiety. Yoga and meditation help in controlling high blood pressure, which keeps mind relax. Yoga has proved to be of great benefit to students suffering from hypertension.

\section{FLEXIBILITY AND WEIGHT MANAGEMENT}

Flexibility of the body is another advantage of doing yoga regularly. Practicing yoga asana your muscles are also stretched thereby increasing the flexibility of your body. Uneasiness in breathing and obesity are some of the problems related to weight which is very common among the students. Due to high calories drinks and food intake, students have to face such types of problems. With practicing yoga regularly they can help their weight management.

\section{ROLE OF ACADEMIC INSTITUTIONS}

Today children and youth are also victims of stress, anxiety, digestive disorders, insomnia, etc., due to a highly competitive environment in School, College, University as well as work place. Peer-pressure, examination pressure, long working hours, irregular eating habits is a few other causes of a stressful lifestyle ${ }^{[1]}$. So learning Yoga has immense benefits on the overall health and well-being of the student community.

Modern day school students have to carry a heavy load of books on their shoulders daily, most of the time they found sitting on the chairs. This marathon of sitting from morning to evening throughout their school life makes their body rigid, hard and stiff. Most of the students lack the much needed flexibility in their physical body. The hardness and rigidness of their body, naturally affect their mind, which in turn affect their studies. They are stuck between school, exams, sports, and many other activities which result in mental and health disorders. Therefore, Yoga helps school students to live a balanced, healthy, and confident life.

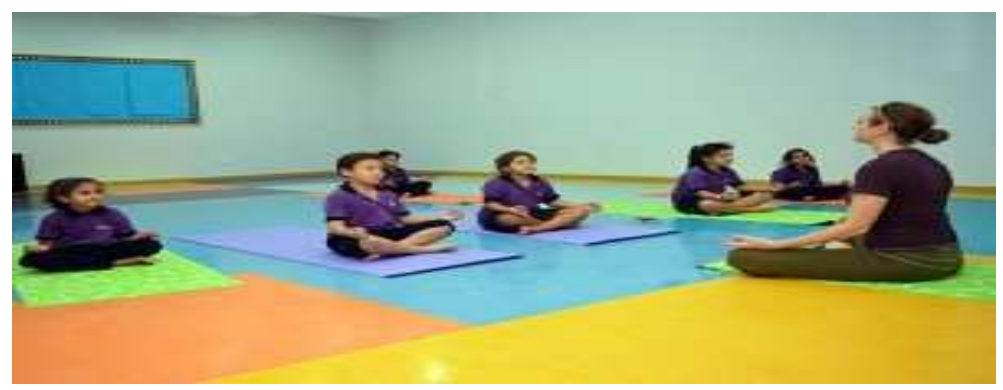

Figure 1

In case of College and University students, they have lots of pressure, they have to write 10 pages in just a few hours, get good grades, have a social life, have to build career ${ }^{[4]}$. For them Yoga can be a effective means to develop them 
as a very good student, nice human being, a relaxed and energetic person and a good citizen in the society. There is the responsibility of Academic Institute (School, College and University) to take some initiatives to promote Yoga. It is therefore not surprising that educational institutes have adopted Yoga as part of their curriculum activities.

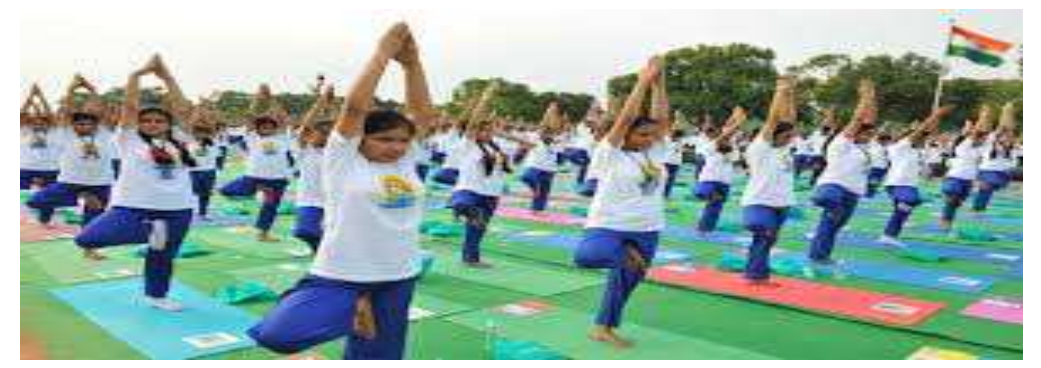

Figure 2

- Recently we have seen that Yoga introduced as a subject in schools from Class VI to X by the Narendra Modi Government. NCERT (National Council of Educational Research and Training) has developed textual material on Yogic activities for students of Upper Primary and Secondary Stage. Even many private schools (over 17,000) are influenced by the Govt. Initiatives regarding Yoga and include Yoga in their syllabus as a part of Physical Education ${ }^{[10]}$.

- Yoga Education is incorporated into the syllabus of D. El. Ed ${ }^{[7]}$, B.Ed. and M.Ed., by NCTE (National Council for Teacher Education) ${ }^{[6]}$.

- Many institutes celebrate International Yoga Day in $21^{\text {st }}$ June in their campus (Such as- Indian Institute of Science, Bangalore, Indian Institute of Technology, Roorkee, IIT, Andhra Pradesh, Babariass Institute of Technology, Vadodara etc).

- We know that Our Hon'ble Prime Minister Mr. Narendra Modi has always been a vocal supporter of yoga. We have seen that PM Narendra Modi is all set to participate in the International Yoga Day 2017 event, the third edition, in $21^{\text {st }}$ June at Uttar Pradesh capital Lucknow's Ramabai Ambedkar Ground. He inspires the world to practice Yoga for healthy life ${ }^{[3]}$.

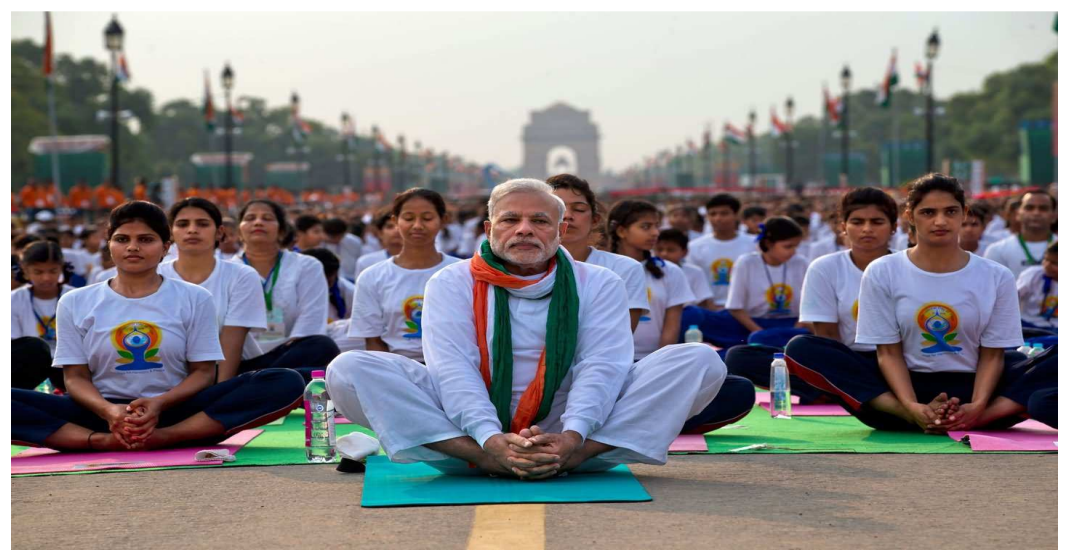

Figure 3

Introduction of Yoga by the Academic Institutions is a welcome move but celebrating it just for one day (International Yoga Day, $21^{\text {st }}$ June) does not serve the purpose. We have to make it mandatory for all students. So, for this 
Govt. has to take some initiatives and with this co-operation of all private institutes is very necessary.

\section{ROLE OF ACADEMIC LIBRARY}

In Academic Institution awareness of practicing Yoga is very important. In this regard Academic Library can play a very positive role. Academic Library (School Library, College Library and University Library) can make aware about the benefit of Yoga among students.

The role of Academic Library to encourage the student community about the importance of Yoga in modern age is as follows:

- Academic library can support the Academic Institutions (viz. School, College, and University) by providing resources related to Yoga. They can provide resources that fall outside the context of regular work or study. The resources that provide information related emotional health and physical health ${ }^{[9]}$.

- By keeping good collection on Yoga, academic library can motivate student community. The resources may comprises of books on Yoga, magazines containing Yoga related content, journals, different audio-visual aids on yoga showing how to do Asanas, Pranayam, Meditation and demonstration of yoga by Yogis.

- Library can also motivate student community by using wall pictures of different Asanas, with their small descriptions.

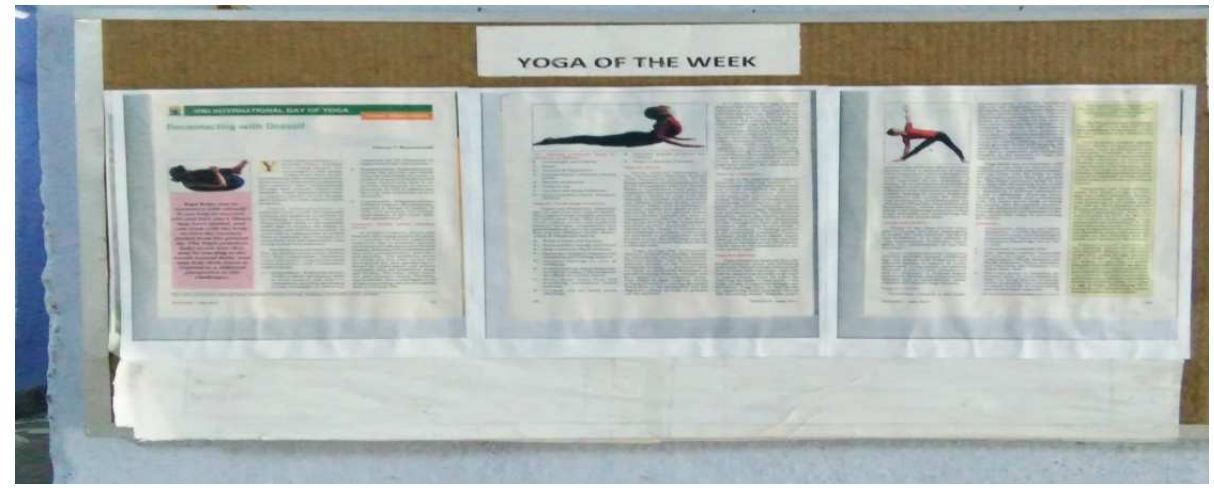

Figure 4

- Library can use small boards on the library walls showing different words related to Yoga to inspire students. Librarian can daily write any yoga related motivational words, tips, quotes on the board to motivate students.

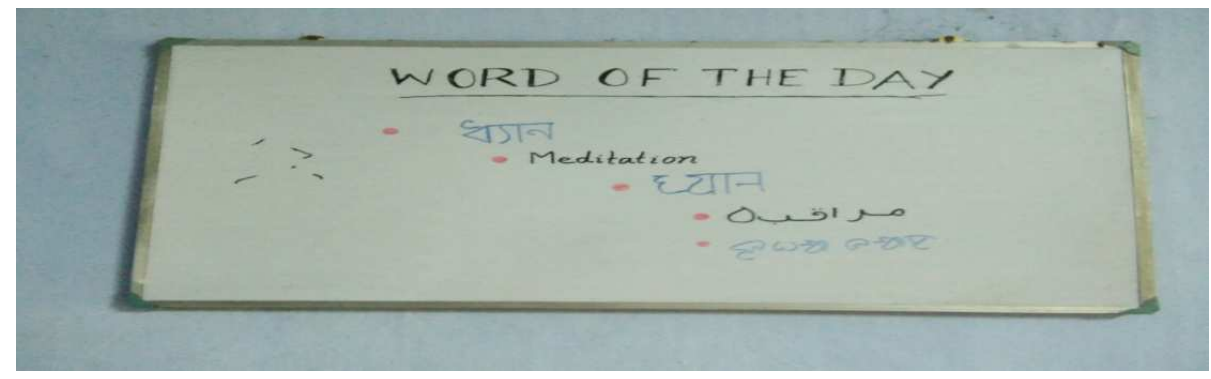

Figure 5

- Librarian can also motivate students by their personal assistance. They personally inspire students by provide information on benefits of Yoga in students life by their knowledge. 
- Library can organize different types of activities relating to Yoga, like small work shop, seminar, informative class on yoga, by projector showing Yoga related information for awareness of students, can celebrating International Yoga day etc.

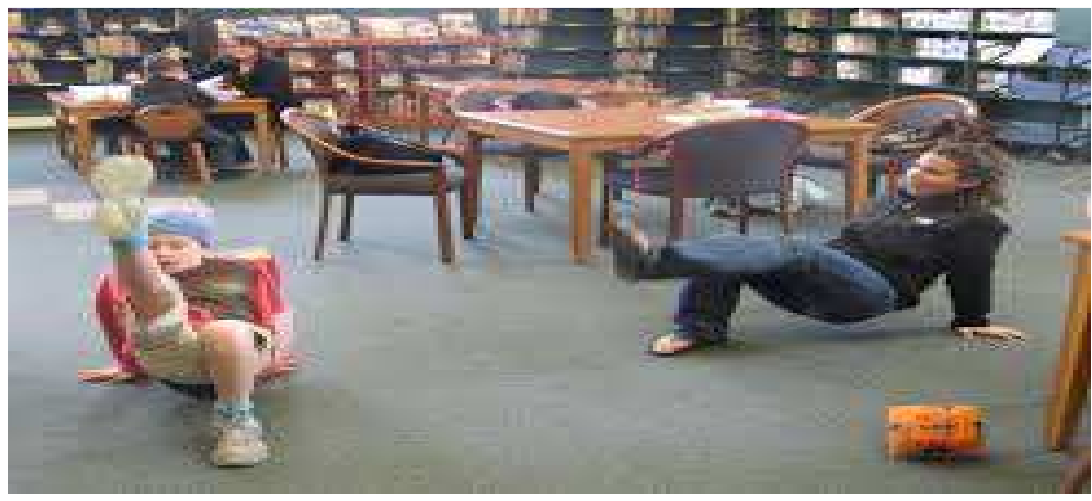

Figure 6

\section{CONCLUSIONS}

Yoga can integrate the body, mind and spirit through a system of Asanas, Pranayam and Meditation ${ }^{[8]}$. It helps to gain control over the mind and so concentration and intelligence of student community increase. So, Yoga can be integrated in the modern system of education starting from lower to higher standard of classes in schools, colleges and universities ${ }^{[2]}$. It should be treated as a boon, not as a burden. Students are the future citizen of the country. So their concentration, memory, intelligence, creativity and physical as well as mental well-being must be taken care of. In this aspect, Academic Institutions as well as Academic Library can perform a very positive role to inspire student community towards practicing Yoga by providing beneficial information. Many initiatives are taken by the Govt. till now but in future Govt. has to take some initiatives to make Yoga compulsory for student community and for this co-operation of all private institutes is very necessary.

\section{REFERENCES}

1. Sivakumar, A \& Pazhanivelu, G (2016). Impact of Yoga and Meditation Among the Student Community. International Journal on Recent and Innovation Trends in Computing and Communication.4 (2).

2. Chen, David Dapeng (2014). Perceived Benefits of Incorporating Yoga into Classroom Teaching: Assessment of the Yoga Tools for Teachers. Advances in Physical Education, 4, (pp. 138-148).

3. REPORT ON CELEBRATION OF INTERNATIONAL YOGA DAY 21ST JUNE 2017(n.d.).Retrieved from http://vnit.ac.in/images/Gallary/Report\% 20on\%20Celebration\%20of\%20International\%20Yoga\%20Day\%2021st\%20June\%202017.PDF

4. REASON WHY COLLEGE STUDENTS NEED YOGA (n.d.). Retrieved from https://www.mindbodygreen.com/0-7396/5reasons-why-college-students-need-yoga.html

5. Hagen, I \& Nayar, US (2014). Yoga for Children and Young People's Mental Health and Well-Being: Research Review and Reflections on the Mental Health Potentials of Yoga. Front Psychiatry,5

6. YOGA EDUCATION - NCTE (n.d.). Retrieved from http://ncte-india.org/ncte_new/pdf/Yoga\%20Education\%20\%20B.Ed\%20-\%20English.pdf 
Role of Academic Library to Encourage Student Community about the

Impact of Yoga in Modern Age: An Overview

7. YOGA EDUCATION - NCTE (n.d.). Retrieved from http://ncte-india.org/ncte_new/pdf/Yoga\%20Education\%20\%20D.El.Ed\%20-\%20English.pdf

8. YOGA: A HEALTHY WAY OF LIVING (n.d.). Retrieved from http://www.ncert.nic.in/gpPDF/pdf/tiyhwlss 1.pdf

9. THE IMPACT OF LIBRARIES AS CREATIVE SPAES $\quad$ (n.d.). Retrieved from http://www.plconnect.slq.qld.gov.au/_data/assets/pdf_file/0003/339717/SLQ-Creative-Spaces-Low-Res.pdf

10. WORLD EDUCATIN SUMMIT (n.d.). Retrieved from http://digitallearning.eletsonline.com/2015/06/smriti-irani-recommendsintroducing-yoga-as-subject-in-schools/

11. YOGA AND ITS IMPORTANCE IN STUDENTS LIFE $\quad$ (n.d.). Retrieved from http://www.studentsassignmenthelp.com/blogs/yoga-importance-students-life/ 
